\title{
Mg-doped AlGaN grown on an AlN/sapphire template by metalorganic chemical vapour deposition
}

\author{
Hongbo Yu ${ }^{*}, 1$, Wlodek Strupinski ${ }^{2}$, Serkan Butun ${ }^{1}$, and Ekmel Ozbay ${ }^{1}$ \\ ${ }^{1}$ Nanotechnology Research Center and Department of Physics, Bilkent University, Bilkent, \\ 06800 Ankara, Turkey \\ 2 Institute of Electronic Materials Technology, 01-919 Warsaw, Poland
}

Received 21 November 2005, revised 1 January 2006, accepted 13 January 2006

Published online 8 March 2006

PACS 73.61.Ey, 81.15.Gh

The growth of high-performance Mg-doped p-type $\mathrm{Al}_{x} \mathrm{Ga}_{1-x} \mathrm{~N}(x=0.35)$ layers using low-pressure metalorganic chemical vapour deposition on an AlN/sapphire template is reported. The influence of growth conditions on the p-type conductivity of the $\mathrm{Al}_{x} \mathrm{Ga}_{1-x} \mathrm{~N}(x=0.35)$ alloy was investigated. It was found that the p-type resistivity of the $\mathrm{AlGaN}$ alloy demonstrates a marked dependence on the $\mathrm{Mg}$ concentration, $\mathrm{V} / \mathrm{III}$ ratio and group III element flow rate. A minimum p-type resistivity of $3.5 \Omega \mathrm{cm}$ for $\mathrm{Al}_{x} \mathrm{Ga}_{1-x} \mathrm{~N}$ $(x=0.35)$ epilayers was achieved. A Ni/Au $(10 \mathrm{~nm} / 100 \mathrm{~nm})$ ohmic contact was also fabricated and a specific contact resistivity of $8.1 \times 10^{-2} \Omega \mathrm{cm}^{2}$ was measured.

() 2006 WILEY-VCH Verlag GmbH \& Co. KGaA, Weinheim

\section{Introduction}

Al-rich AlGaN alloys are currently attracting much attention since they are particularly suited for the realization of deep ultraviolet (UV) optoelectronic devices, such as light emitting diodes, laser diodes, and solar-blind photodetectors [1-3]. To obtain high performance from these devices, highly conductive n-type and p-type $\mathrm{AlGaN}$ alloys with high $\mathrm{Al}$ fraction are indispensable. However, compared to $\mathrm{GaN}$, it is even more difficult to control the conductivity through doping in AlGaN alloys due to a higher concentration of defects and larger ionization energy of the dopants [4]. The fabrication of p-type AlGaN with high Al content is still a significant challenge. A compromise can be reached by using methods $[5,6]$ such as $\mathrm{Mg}$ delta doping and $\mathrm{Mg}$-doped strained $\mathrm{AlGaN} / \mathrm{GaN}$ superlattices. Several groups have reported successful metalorganic chemical vapour deposition (MOCVD) growth of uniform p-type Al$\mathrm{GaN}$ epitaxial layers using $\mathrm{Mg}$ as a dopant [7-11]. Most investigations have focused on p-type AlGaN epilayers with an $\mathrm{Al}$ fraction that is less than 20\%. Li et al. [12] obtained $\mathrm{Mg}$ acceptor activation energies $E_{\mathrm{A}}$ of $\mathrm{AlGaN}$ alloy with an $\mathrm{Al}$ content of up to 0.27 , and deduced that at an $\mathrm{Al}$ content of $x=0.45$ the resistivity should be as high as $2.2 \times 10^{4} \Omega \mathrm{cm}$. Recently, Jeon et al. [13] reported p-type resistivity as low as $10 \Omega \mathrm{cm}$ in $\mathrm{AlGaN}$ epitaxial layers with an $\mathrm{Al}$ content of 0.3 . The electrical characteristics of group III nitride epitaxial films are sensitive to the MOCVD growth conditions. It is therefore important to investigate the effect of growth parameters on the performance of p-type AlGaN.

In this paper we demonstrate the MOCVD growth conditions suitable for fabricating p-type AlGaN epilayers with high $\mathrm{Al}$ fraction. Based on electrical investigations of $\mathrm{Al}_{x} \mathrm{Ga}_{1-x} \mathrm{~N}(x=0.35)$ epilayers, a minimum p-type resistivity of $3.5 \Omega \mathrm{cm}$ is achieved.

\footnotetext{
"Corresponding author: e-mail: yu@fen.bilkent.edu.tr, Phone: +90 312290 1020, Fax: +90 3122901015
} 


\section{Experimental}

Mg-doped AlGaN epitaxial layers were grown in a low-pressure MOCVD reactor (Aixtron 200/4 HT-S). Trimethylgallium (TMGa), trimethylaluminium (TMAl), ammonia, and biscyclopentadienylmagnesium $\left(\mathrm{Cp}_{2} \mathrm{Mg}\right)$ were used as $\mathrm{Ga}, \mathrm{Al}, \mathrm{N}$, and $\mathrm{Mg}$ precursors, respectively. A $15 \mathrm{~nm}$ thick, low-temperature $\left(600{ }^{\circ} \mathrm{C}\right) \mathrm{AlN}$ nucleation layer was deposited on a double-polished 2-inch $(0001) \mathrm{Al}_{2} \mathrm{O}_{3}$ substrate prior to the growth of a high-temperature $\left(1150{ }^{\circ} \mathrm{C}\right) 0.7 \mu \mathrm{m}$ AlN template and $0.1 \mu \mathrm{m}$ undoped AlGaN transitional layer. On top of these structures, $0.3 \mu \mathrm{m}$ thick Mg-doped $\mathrm{AlGaN}$ layers were grown using different growth parameters. There were no other additional conductive layers that might influence the conductivity measurements.

UV optical transmission measurements were carried out using an Ocean Optics CHEM2000-UV-VIS PC plug-in fibre optic spectrophotometer in the $200-600 \mathrm{~nm}$ range. X-ray diffraction was performed using a Bruker $\mathrm{D} 8$ system, delivering a $\mathrm{Cu} \mathrm{K}_{\alpha 1}$ line. Current-voltage $(I-V)$ transmission line model (TLM) measurements and Hall measurements (commercial Lakeshore model 7512 Hall Measurement System) were carried out to obtain the resistivity of the Mg-doped AlGaN layers. A Ni/Au $(10 \mathrm{~nm} /$ $100 \mathrm{~nm}$ ) metallization contact was fabricated on the p-type AlGaN surface for the Hall measurements. Prior to the Hall measurements, the ohmic behaviour of the contacts was verified by means of $I-V$ characteristics. The resistivity values from the Hall measurements were in general consistent with those from the TLM measurements. $I-V$ measurements were carried using an HP 4142B modular DC source.

To explore the influence of the growth conditions on the electrical properties of the p-type AlGaN epilayers, two series of Mg-doped AlGaN layers were grown. The TMGa flow rate was 22.5 and $40.4 \mu \mathrm{mol} / \mathrm{min}$ for the first and second series, respectively. The Al fraction in the AlGaN alloy was maintained at $35 \%$ in all of the samples by adjusting the TMAl flow rates to 6.7 and $17.9 \mu \mathrm{mol} / \mathrm{min}$. During the growth of the $\mathrm{AlGaN}$ layers, the reactor pressure and growth temperature were kept at 50 mbar and $1050^{\circ} \mathrm{C}$, respectively.

\section{Results and discussion}

In order to determine the $\mathrm{Al}$ content and crystal quality of the Mg-doped AlGaN alloy, UV optical transmission was used for selected as-grown samples. As shown in Fig. 1, the optical transmission spectrum shows a sharp cut-off at $284 \mathrm{~nm}$ along with well-defined Fabry-Perot oscillations due to the high quality of the material and smooth surface. One key to obtain high crystal quality of the AlGaN epilayers is the introduction of the AlN buffer. The benefits of applying an AlN epitaxial layer as buffer for defect

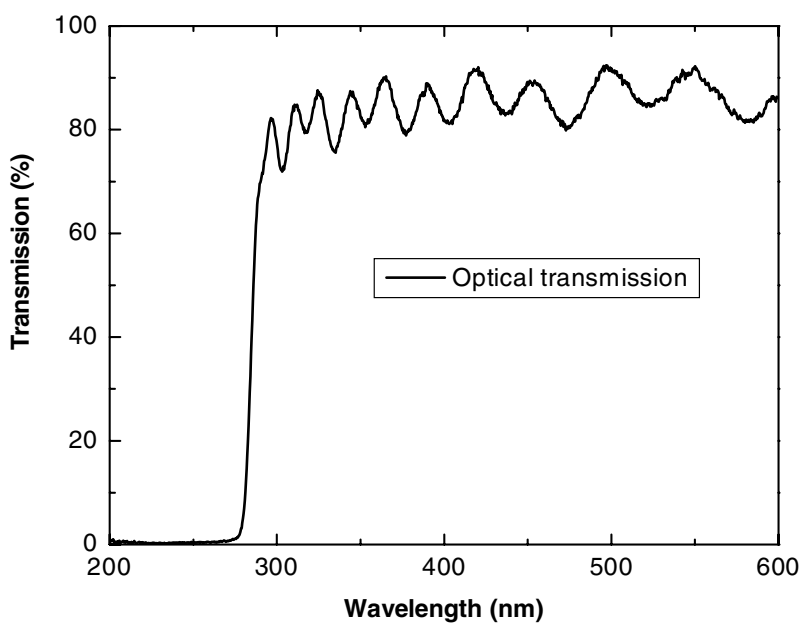

Fig. 1 Optical transmission of the as-grown Mg-doped AlGaN layer. 


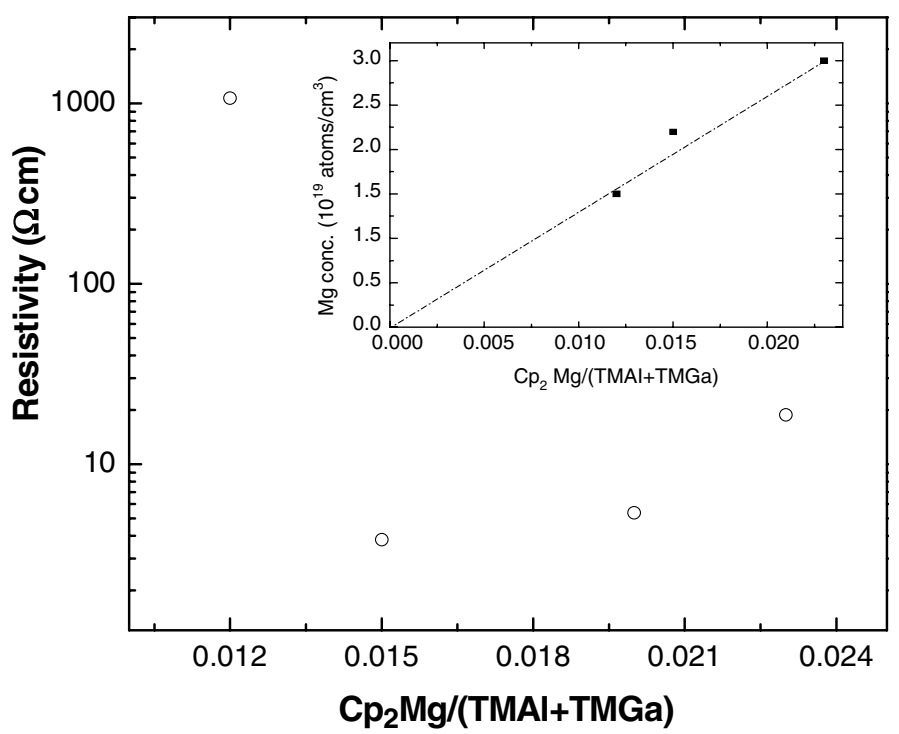

Fig. 2 Variation of p-type $\mathrm{AlGaN}$ resistivity with the $\mathrm{Cp}_{2} \mathrm{Mg} /(\mathrm{TMAl}+\mathrm{TMGa})$ mole flow ratio. The inset shows the dependence of $\mathrm{Mg}$ concentration of the samples on the $\mathrm{Cp}_{2} \mathrm{Mg} /(\mathrm{TMAl}+\mathrm{TMGa})$ ratio.

density reduction in $\mathrm{AlGaN}$ have been demonstrated previously [14, 15]. GaN and AlN single layers were also measured using the same apparatus, and a value of $b=0.62 \mathrm{eV}[16]$ was used for the bowing parameter. From the optical characteristics and calculations, we determined the Al content in the AlGaN alloy to be around $35 \%$.

After growth, the Mg-doped samples were thermally activated in $\mathrm{N}_{2}$ at $850{ }^{\circ} \mathrm{C}$ for $10 \mathrm{~min}$, which resulted in p-type conduction verified by a Hall measurement (standard Van Der Pauw). Figure 2 shows the variation of room temperature resistivity with the $\mathrm{Cp}_{2} \mathrm{Mg} /(\mathrm{TMAl}+\mathrm{TMGa})$ mole flow ratio. The measured resistivity has a value of $1070 \Omega \mathrm{cm}$ when the $\mathrm{Cp}_{2} \mathrm{Mg} /(\mathrm{TMAl}+\mathrm{TMGa})$ mole flow ratio is about $1.2 \times 10^{-2}$, and reduces sharply to $3.5 \Omega \mathrm{cm}$ with the mole ratio increases to $1.5 \times 10^{-2}$. With a further increase of the mole ratio, the resistivity begins to increase gradually. Jeon et al. [13] reported the viability of low-resistivity p-AlGaN doping is constrained by two competing mechanisms, namely a minimum dosage of $\mathrm{Mg}$ acceptors required to overcome the background defects and a doping ceiling above which structural defects occur with accompanying degradation of electrical conductivity. The resistivity variation trends for our samples are consistent with these reported results. The incorporation of $\mathrm{Mg}$ during AlGaN growth was studied using secondary ion mass spectroscopy (SIMS), measurements for which were carried out at Charles and Evan Inc. The inset of Fig. 2 shows the measured Mg concentration in $\mathrm{AlGaN}$ samples grown with various $\mathrm{Cp}_{2} \mathrm{Mg} /(\mathrm{TMAl}+\mathrm{TMGa})$ mole flow ratios. As expected, the $\mathrm{Mg}$ concentration is found to increase linearly with the mole ratio. The SIMS measurements indicate that the $\mathrm{Mg}$ doping in $\mathrm{AlGaN}$ epiayers using $\mathrm{Cp}_{2} \mathrm{Mg}$ is a quite well-controlled process within the range of the experiment. Also, it is noted that there is no dependence of common impurity, such as $\mathrm{C}$ and $\mathrm{O}$, incorporation on the $\mathrm{Mg}$ doping process [17].

Figure 3 summarizes the room temperature resistivity of the samples from both series as a function of the V/III molar ratio. The $\mathrm{Cp}_{2} \mathrm{Mg} /(\mathrm{TMAl}+\mathrm{TMAl})$ flow was kept constant so that the nominal doping concentration was not significantly different for all the samples. According to SIMS measurements of selected samples, the Mg concentration in the films is around $2.2 \times 10^{19} / \mathrm{cm}^{3}$. The V/III ratio was calibrated by changing the ammonia flow. As shown in Fig. 3, the variation of the resistivity as a function of $\mathrm{V} / \mathrm{III}$ molar ratio shows a similar trend for both series, indicating that the resistivity of the p-type AlGaN alloy has a marked dependence on the V/III ratio. For the first series, the Mg-doped AlGaN has a high resistivity $\left(>10^{7} \Omega \mathrm{cm}\right)$ at a V/III ratio of 610 , and a minimum resistivity of $89.3 \Omega \mathrm{cm}$ at a V/III ratio of 


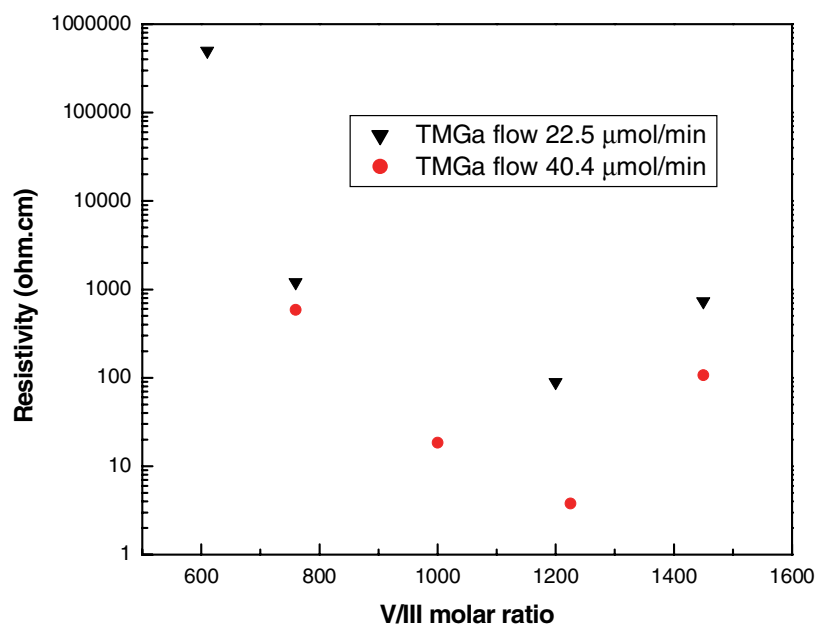

Fig. 3 (online colour at: www.pss-a.com) Resistivity of the p-type $\mathrm{Al}_{x} \mathrm{Ga}_{1-x} \mathrm{~N}(x=0.35)$ epilayers as a function of the V/III molar ratio and group III element flow.

1200. The decrease of the resistivity of the samples with increasing V/III ratio is consistent with the compensation by nitrogen vacancies in the p-type doping of GaN [18]. Compared to the first series, the resistivity of the second series was much lower (more than one order of magnitude) which was due to the increase of the group III element precursor flow (namely the growth rate) at the same V/III ratio. The minimum resistivity $(3.5 \Omega \mathrm{cm})$ was achieved at a V/III ratio of 1225 . Above a V/III ratio of about 1200 , the resistivity values starts to increase for both series.

The exact mechanism responsible for the growth rate effect is not clear at this time. The possibility of compensation through incorporation of an external impurity was checked using SIMS measurements for $\mathrm{C}, \mathrm{O}, \mathrm{H}$, and $\mathrm{Si}$. The results show that the impurity concentrations in the two sample series are not markedly different. It is well known that a high V/III ratio should be maintained in order to achieve highconductivity p-type GaN films, because compensation by nitrogen vacancies plays an important role [18]. Experimental results showed that $\mathrm{GaN}$ growth under N-rich conditions not only increases the Mg incorporation rate but also ensures that the $\mathrm{Mg}$ is incorporated into substitutional Ga sites [19]. However, a relatively low V/III ratio should be used to obtain high crystalline quality AlGaN epilayers, by increasing the surface mobility of adsorbed $\mathrm{Al}$ species. We speculate that $\mathrm{Mg}$ atoms are more likely to replace the Ga or

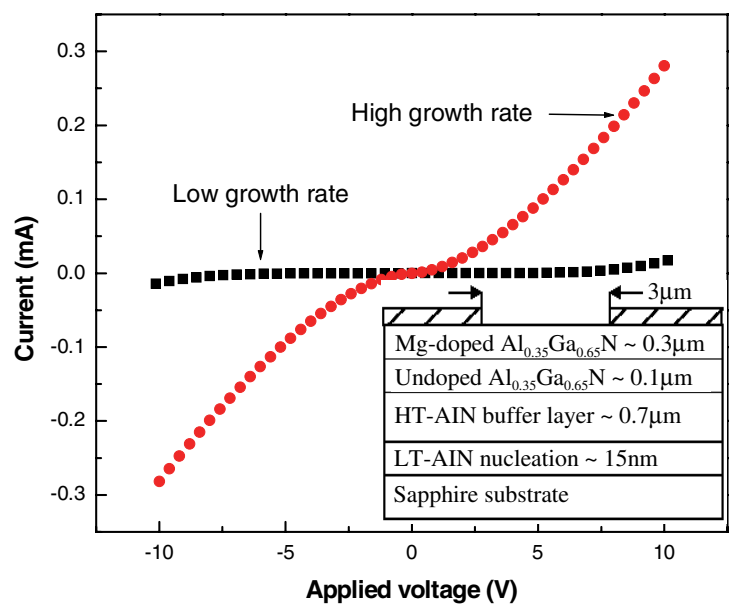

Fig. 4 (online colour at: www.pss-a.com) $I-V$ characteristics of the ohmic contacts to the p-type $\mathrm{Al}_{0.35} \mathrm{Ga}_{0.65} \mathrm{~N}$ epilayers. 
Al sites during AlGaN growth with a relatively high growth rate process, which is essential for the desired acceptor behaviour.

Uniform Mg-doped GaN epilayers typically exhibit p-type resistivity of about $1 \Omega \mathrm{cm}[5]$. Our experimental results reveal that we realized p-type $\mathrm{Al}_{x} \mathrm{Ga}_{1-x} \mathrm{~N}(x=0.35)$ epilayers with a room temperature resistivity as low as 3.5 times more than the typical resistivity of p-type GaN epilayers. We ascribe the enhanced conductivity performance of p-type AlGaN to the following two factors: (i) improvement of AlGaN crystal quality by applying the AlN buffer layer to reduce the compensation effect from defects and scattering centres in the AlGaN epilayers; and (ii) optimization of Mg-doped AlGaN growth conditions, including appropriate $\mathrm{V} / \mathrm{III}$ molar ratio and $\mathrm{Mg}$ doping concentration and a relatively high growth rate.

TLM patterns were deposited using a Ni/Au $(10 \mathrm{~nm} / 100 \mathrm{~nm})$ alloy as ohmic contact metal. The asdeposited ohmic contacts showed non-linear behaviour for both sample series. The linearity of the $I-V$ curves significantly improved after an anneal step that consisted of $60 \mathrm{~s}$ at $700{ }^{\circ} \mathrm{C}$ and $120 \mathrm{~s}$ at $850{ }^{\circ} \mathrm{C}$ in flowing $\mathrm{N}_{2}$ ambient. Figure 4 shows the measured $I-V$ characteristics between two $100 \mu \mathrm{m} \times 200 \mu \mathrm{m}$ TLM pads separated by a $3 \mu \mathrm{m}$ gap. Compared to the samples with a low growth rate (TMGa flow $22.5 \mu \mathrm{mol} / \mathrm{min}$ ), the $I-V$ characteristics of the samples with a high growth rate (TMGa flow $40.4 \mu \mathrm{mol} / \mathrm{min}$ ) exhibited more linear-like characteristics due to the low sheet resistivity of the p-type AlGaN layer. The TLM measurements yielded a specific ohmic contact resistivity of $8.1 \times 10^{-2} \Omega \mathrm{cm}^{2}$. Although this is a significantly low ohmic contact resistivity, further work should be conducted to improve the ohmic contact characteristics of p-type AlGaN epilayers with high $\mathrm{Al}$ fractions.

\section{Conclusions}

We have demonstrated p-type conductivity in Mg-doped $\mathrm{Al}_{x} \mathrm{Ga}_{1-x} \mathrm{~N}(x=0.35)$ epilayers with very low impurity concentrations. The influence of growth conditions (V/III ratio, Mg doping concentration, and group III element flow rate) on the p-type conductivity was investigated. It was found that an appropriate $\mathrm{V} / \mathrm{III}$ mole ratio and $\mathrm{Mg}$ doping concentration and a relatively high growth rate were needed to improve the electrical characteristics of the p-type AlGaN epilayers. A p-type resistivity of $3.5 \Omega \mathrm{cm}$ for $\mathrm{Al}_{x} \mathrm{Ga}_{1-x} \mathrm{~N}(x=0.35)$ was obtained under the optimized growth conditions.

Acknowledgements This work was supported by EU-DALHM, EU NOE-METAMORPHOSE, EU NOEPHOREMOST, and TUBITAK under project no. 104E090. One of the authors (E.O.) acknowledges partial support from the Turkish Academy of Sciences. The authors acknowledge Erkin Ulker for the optical measurements and Dr. Temel Buyuklimanli (Charles and Evan Inc.) for the SIMS measurements.

\section{References}

[1] J. P. Zhang, X. Hu, Y. Bilenko, J. Deng, A. Lunev, R. Gaska, M. Shatalov, J. Yang, and M. A. Khan, Appl. Phys. Lett. 85, 55 (2004).

[2] S. Ito, Y. Yamasaki, S. Omi, K. Takatani, T. Kawakami, T. Ohno, M. Ishida, Y. Ueta, T. Yuasa, and M. Taneya, Jpn. J. Appl. Phys. 43, 96 (2004).

[3] R. McClintock, A. Yasan, K. Mayes, D. Shiell, S. R. Darvish, P. Kung, and M. Razeghi, Appl. Phys. Lett. 84, $1248(2003)$

[4] T. Tanaka, A. Watanabe, H. Amano, Y. Kobayashi, I. Akasaki, S. Yamazaki, and M. Koike, Appl. Phys. Lett. 65, 593 (1994).

[5] M. L. Nakarmi, K. H. Kim, J. Li, J. Y. Lin, and H. X. Jiang, Appl. Phys. Lett. 82, 3041 (2003).

[6] P. Kozodoy, M. Hansen, S. P. DenBaars, and U. K. Mishra, Appl. Phys. Lett. 74, 3681 (1999).

[7] T. Tanaka, A. Watanabe, H. Amano, Y. Kobayashi, I. Akasaki, S. Yamazaki, and M. Koike, Appl. Phys. Lett. 65, 593 (1994).

[8] M. L. Nakarmi, K. H. Kim, M. Khizar, Z. Y. Fan, J. Y. Lin, and H. X. Jiang, Appl. Phys. Lett. 86, 092108-1 (2005).

[9] M. Suzuki, J. Nishio, M. Onomura, and C. Hongo, J. Cryst. Growth 189, 511 (1998). 
[10] G. Kipshidze, V. Kuryatkov, B. Borisov, Y. Kudryavtsev, R. Asomoza, S. Nikishin, and H. Temkin, Appl. Phys. Lett. 80, 2910 (2002).

[11] R. Y. Korotkov, J. M. Gregie, and B. W. Wessels, Appl. Phys. Lett. 78, 222 (2001).

[12] J. Li, T. N. Oder, M. L. Nakarmi, J. Y. Lin, and H. X. Jiang, Appl. Phys. Lett. 80, 1210 (2002).

[13] S.-R. Jeon, Z. Ren, G. Cui, J. Su, M. Gherasimova, J. Han, H.-K. Cho, and L. Zhou, Appl. Phys. Lett. 86, 082107 (2005).

[14] S. Arulkumaran, M. Sakai, T. Egawa, H. Ishikawa, T. Jimbo, T. Shibata, K. Asai, S. Sumiya, Y. Kuraoka, M. Tanaka, and O. Oda, Appl. Phys. Lett. 81, 1131 (2002).

[15] B. Zhang, T. Egawa, H. Ishikawa, Y. Liu, and T. Jimbo, J. Appl. Phys. 95, 3170 (2004).

[16] S. R. Lee, A. F. Wright, M. H. Crawford, G. A. Petersen, J. Han, and R. M. Biefeld, Appl. Phys. Lett. 74, 3344 (1999).

[17] Hong Bo Yu, E. Ulker, and E. Ozbay, accepted by J. Cryst. Growth.

[18] P. Kozodoy, S. Keller, S. P. DenBaars, and U. K. Mishra, J. Cryst. Growth 195, 265 (1998).

[19] J. W. Orton, C. T. Foxon, T. S. Cheng, S. E. Hooper, S. V. Novikov, B. Ya. Ber, and Yu. A. Kudriavtsev, J. Cryst. Growth 197, 7 (1999). 